\title{
Exploration of Attitude Change Theory in Online Public Opinion Guidance
}

\author{
Yi ZHANG ${ }^{1}$, Chen WU*1, Fei LIU ${ }^{1}$ \\ ${ }^{1}$ College of Information and Communication National University of Defense Technology Xi'an, China
}

\begin{abstract}
Online public opinion is the representation of social public opinion on the internet space and a direct reflection of social public opinion. The essence of network public opinion guidance is to influence and change the attitude of Internet users through a series of strategies, so as to effectively control the influence trend and scope of public opinion. How netizen's opinions change and how to facilitate those changes are at the core of online public opinion control and guidance.
\end{abstract}

\section{Introduction}

In social psychology, attitude change refers to the change of a certain formed attitude upon receiving a piece of information or under the influence of a certain point of view ${ }^{[1]}$. Its essence is the continuous socialization of an individual $^{[2]}$. Some mature theories that describe such attitude change include social judgment theory, threestage attitude change theory and the persuasive ability based "change-persuasion" theory.

According to social judgment theory, the attitude that one individual holds can be symbolized with an area which comprises of the acceptance area, unclear-attitude area and rejection area. When an individual encounters a piece of persuasive information or a new view, he will first make a judgment and find out which part of his attitude field information or opinions belong to .Then he can make responses based on the above principles on whether to embrace or reject the change. If through judgment, he finds that the new view or belief is within the range of his "acceptance area", he will likely accept it and change his previous attitude accordingly. Besides, when the new view or belief is categorized into the "unclear area", his original assumption will also go through changes.

The "three-stages" theory believes that attitude change should go through the following three stages: First, the compliance stage. Compliance is an act that people are forced to take in order to get material or spiritual rewards or avoid punishment. Acts of compliance are not voluntary actions but rather temporary behaviors taken under external pressure. Since they are greatly influenced by exterior factors, once the influences from outside are gone, they will be abandoned immediately. Second, the assimilation stage, where an individual is willing to accept views or beliefs or new information from others and bring his attitude closer to the requirements of others. In this stage, since the individual has identified with the group he belongs to in the assimilation process, he will naturally adopt an attitude or behavior similar to that of other members. But in this phase, his new attitude has not yet blended in with his existing attitude system. Third, the internalization stage, where the individual truly believes and accept others' view from the depth of his heart and changes his former attitude. Since he adopts the new view and thoughts, it means that he has included them into his own value system and made them an organic part of his attitude system too. It is in this stage that attitude change actually begins.

The "change-persuasion" theory is based on the information dissemination theory, which believes that in the process of information transmission the major factors affecting attitude change are: the reliability of the information sent by the sender, the content structure of the information, the features of the recipient, and whether the recipient is involved in the transmission process ${ }^{[3]}$. Considering the features of online public opinion transmission and the aim of control strategy, we think that it is more proper to base the research and formulation of online public opinion control strategies on the "changepersuasion" theory.

\section{Basic issues of the attitude "change- persuasion" theory}

How does the reliability of the transmitter influence the attitude change of the receiver? Those who are considered more authoritative in the field he is talking about seem to have greater influence than those who are less authoritative. The so-called authority can be divided into 3 groups: those who enjoy a wide reputation, those who are experts and those who are considered impartial. Besides, if the receiver likes the transmitter, he is likely to be persuaded $^{[4]}$.

With regard to disputed issues, which method is more persuasive: one-sided presentation or dual-sided argumentation from both the positive and negative sides? 
Generally, if the receiver holds the same view as the transmitter, one-sided presentation is enough; however, if the receiver's views contradict with the transmitter's, a combination of positive and negative argumentation is preferable; the latter technique should also be adopted when the receiver is well-educated; on the contrary, when the receiver is poorly-educated, one-sided presentation is enough; however, for poorly-educated receivers whose views seem to be in line with those of the transmitter, onesided presentation is recommended for dual-sided presentation will add to their uncertainty.

In what way should a question be asked (with fear, emotion or sensibility) in order to be more persuasive? When it comes to changing someone's attitude, the socalled techniques such as "good rhetoric and humor" seem apparently ineffective. However, repeating a single argument seems to be able to produce the desired effect within a short time. Plus, an emotional appeal is more conducive to attitude change compared with one given with reason ${ }^{[5]}$. When making use of people's fear as a means of persuasion technique, the degree of fear is related to attitude change: fear at mild and intermediate levels is more effective, while too intense fear will likely be rejected by the receiver.

Where should a question be asked? Earlier or later? Usually, when the question is asked earlier, it will arouse more attention; but a question raised in the end will be remembered more easily; If the question is consistent with the view of the receiver, it is better asked earlier; when an argument is made from both sides, questions put forward earlier are likely to be influenced; However, if some irrelevant contents are inserted between two questions, the latter question will be influenced; If the aim of the transmission is to arouse and satisfy demands at the same time, the transmitter should arouse the demand of the receiver first before posing his question ${ }^{[6]}$. If the receiver is unfamiliar with the questions, the transmitter should list the focal points of his question.

Should the conclusion be given explicitly or subtly? It is generally believed that an explicit conclusion is more acceptable to the receiver.

How does the receiver's personality affect attitude change? Generally, an aggressive person is hard to persuade, so is a man with eccentric personality; People who are imaginative and sensitive are easier to persuade, while those with poor imagination and slowness in brain are harder to persuade. People who have a low self-esteem is more easily persuaded than those with high self-esteem.

\section{Basic issues of the attitude "change- persuasion" theory}

The attitude "change-persuade" theoretical model is presented as follows:
Table1. The attitude "change-persuade" theoretical model Table Column Head The attitude "change-persuade" theoretical model

\begin{tabular}{|l|l|l|l|}
\hline the & \multicolumn{2}{|c|}{ model } \\
persuader & $\begin{array}{l}\text { persuasion } \\
\text { information }\end{array}$ & $\begin{array}{l}\text { The } \\
\text { receiver }\end{array}$ & $\begin{array}{c}\text { persuasion } \\
\text { scenario }\end{array}$ \\
\hline Authority & $\begin{array}{l}\text { Information } \\
\text { divergence }\end{array}$ & $\begin{array}{l}\text { Existing } \\
\text { attitude }\end{array}$ & Warning \\
\hline Intention & $\begin{array}{l}\text { Information } \\
\text { emotionality }\end{array}$ & $\begin{array}{l}\text { Mental } \\
\text { immunity }\end{array}$ & Distraction \\
\hline Attractivenes & $\begin{array}{l}\text { Information } \\
\text { organization }\end{array}$ & $\begin{array}{l}\text { Character } \\
\text { features }\end{array}$ & Repetition \\
\hline
\end{tabular}

After an analysis of this model, we can conclude that the persuader, persuasion information, receiver and persuasion scenario make up the four basic elements of attitude change, among which the persuader, persuasion information and persuasion scenario comprise the external stimulants of attitude change.

\subsection{The persuader}

- $\quad$ Authority. The authority of the persuader as well as his similarity with the receiver can both have an impact on the persuasiveness of the information he offers. The more authoritative he is, and the greater the similarity he shares with the receiver, the better the persuasion effect.

- Intention. If the receiver believes that the transmitter is trying to influence him on purpose, he will not give up his attitude easily; on the contrary, if he believes that the transmitter has no intention to control him, he will not resist him psychologically and he is more likely to accept the information or change his attitude.

- Attractiveness. The receiver identifies better with highly attractive persuaders and therefore more open to his persuasion.

\subsection{Persuasion information}

- Divergence. Any attitude change occurs when there exists a divergence between the persuasion information and the original attitude the receiver holds. The more authoritative the persuader and the greater the divergence, the more drastic the attitude change will be; however, if the persuader has a lower degree of authority but the divergence is still moderate, the attitude change will also be dramatic.

- Emotionality. The less emotion that the persuasion information contains, the more objective and reliable it will be and the greater the attitude change will be; the more emotional the persuasion, the less objective and reliable it will be and the effect of attitude change it cause will be lower.

- Organization. For the general public, unidirectional information has greater effectiveness of persuasion, while for welleducated information receiver, providing information on both positive and negative sides tend to have better effects. 


\subsection{Receiver}

- Existing attitude. Existing attitude has been internalized as part of the receiver's belief and is hard to change. It has become an established fact. Therefore, an attitude formed based on direct experience can not be changed easily.

- Mental immunity. When faced with pressure to change his attitude, an individual tends to reject external influence under the influence of his rebelliousness, psychological inertia and the tendency to keep his face, all of which will influence his attitude change. People tend to adopt some self-defense strategies to lessen the influence of persuasion information on themselves, for example, rejecting generally, disparaging the source, distorting the information and refuting the argument.

- Character features. Receivers who have a high degree of dependency tend to believe in the authority and are more ready to be persuaded, while receivers with high self-esteem and selfassessment tend to stick to their own beliefs.

\subsection{Scenario}

- Warning. If the receive is not firm with his stance, a warning in advance can help change his attitude, but a warning can also have the opposite effect. For example, when the warning is related to his personal interests, he is more likely to resist against attitude change.

- Distraction. If the distraction distracts the receiver's attention on the information, it will weaken his defense and resistance against the persuader and facilitate an attitude change; if the distraction interferes with the persuasion process and prevents the receiver from getting the right information, the persuasion effect will be impaired.

- Repetition. The relationship between the repetition frequency of the communicated information and the persuasive effect is an inverted $U$ shape. That is to say, repetition at intermediate frequency has the best effect; if the repetition frequency is too high or too low, the persuasive effect will not be good.

In the process of attitude change, the persuader must first of all design a set of "persuasion information" in order to persuade others to adopt the same views; next, the receiver needs to learn the contents of the information. During the process of studying, transference will occur, namely, the receiver will transfer his emotions for a certain object to other related objects. When receiving information from others, people will begin to conduct a series of thinking automatically. These reactions will further decide the individual's general response to the information. When the received information disagrees with the receiver's existing attitudes, he will experience mental nervousness. This is the time when mental immunity begins to function. The consistency theory believes that people can take various measures to lessen the anxiety, among which refutation is one of the effective ways to ease the tension. The quantity and nature of refutations in response to the information plays a decisive role on attitude change. If the refutation process is disrupted, then persuasion effect will be achieved and the attitude of the object of persuasion will be altered; otherwise the object will take up all kinds of defensive means like disparaging the source of the information, distorting, rejecting or covering up the information to fight against the persuasion and defend his original attitude.

\section{Application of the attitude change- persuasion model}

\subsection{Public commitment}

- Public commitment refers to the opinions and stance declared by individuals in public. Those who make public commitment are often more determined about their stance and better at handling the impact of the subsequent information. At the same time, they are more susceptible to the information that represents the same attitudes with them ${ }^{[7]}$. Mostly, public commitment is more lasting and stable than the private one ${ }^{[8]}$, because it enhances the confidence of individuals in their attitudes and sets targets for the subsequent behaviors, which exerts strong binding force on the changes in the attitudes of individuals.

- Individuals will be in a stress defense state when their public attitude and stance are challenged by the conflicting ones, thus ensuring the consistence of individual preferences or speeches and behaviors. They will then process the conflicting attitudes and neglect the information that is against their public commitment.

- Public commitment influences the attitude-change in several ways. Factors such as attitude certainty, event importance and preference consistency all increase the anti-persuasion of the public commitment. Therefore, individuals should avoid the impact of opposite attitude when making decisions and clearly state their attitude in public, thus better overcoming the impact of persuasion.

\subsection{Self-control}

- Individual decisions are often subject to the impact of persuasion. To safeguard the previous decisions or avoid the adverse impact from the change in stance and attitude, one should have both the will and the capacity to resist persuasion. Self-control represents the ability or resource to meet this end. To resist the impact of persuasion, one needs to make efforts and have clear goals, i.e. self-control resources. When such resources are absent, individuals will be less or not capable of resisting persuasion and change attitudes easily. Selfcontrol is a depletable resource ${ }^{[9]}$, which may diminish as individuals leverage it to meet their goals. 
- The abundance of the self-control resource decides whether individuals can stick to their original attitude in face of persuasive information. To avoid the impact of persuasion, individuals must have sufficient self-control resource and make good use of it so as to maintain independent stance and attitude.

\subsection{Repetitive persuasion}

- According to social psychologists, when a new attitude is strong and radical, attitude change is likely to take place. The more frequent such attitude is presented, the more influential it will $\mathrm{be}^{[10]}$.

- Compared with the information mentioned at one time, the information brought by three times is more easily accepted by individuals. However, when the frequency increases, the information will be less convincing. There are many causes to this phenomenon. One possible explanation is that individuals will not evaluate the consistency of the information when analyses are made repeatedly. Boredom also breeds the passive attitude towards the information. Another cause can be psychological resistance, which appears when individuals feel that their freedom of choice is threatened.

- During attitude-change, the times of repetition decide the outcome of persuasion. Mostly, the more complicated the information is, the more repetition will be needed; because information is processed based on the evaluation of information consistency. Slight changes in the information, i.e. the variant of the information under the same topic, can help avoid the shift from positive response to negative response.

\section{References}

1. Shen Heyong. The Principles and Application of Social Psychology,3rd ed., Guangzhou: Ji'nan University Press, 1999,pp.111.

2. Zhang Houcan. College Psychology,3rd ed.,Beijing:Beijing Normal University Press, 2001, pp,276.

3. Sherif,C.W,Social categorization as a function of latitude of acceptance and series range. Journal of Abnormal and Social Psychology,1963,67(8), pp148156

4. Caballero, J., James, R. L., \& Charles, S. M. Using physical attractiveness as an advertising tool: An empirical test of the attractiveness phenomenon. Journal of Advertising Research, 1989,29(4), pp1622.

5. DeSteno, D., Petty, R. E., Rucker, D. D., Wegener, D. T., \& Braverman, J. Discrete emotions and persuasion: The role of emotion-induced expectancies. Journal of personality and Social Psychology,2004,86(1),pp4356.
6. Meyerowitz, B. E., \& Chaiken, S. The effect of message framing on breast self-examination attitudes, intentions, and behavior. Journal of Personality and Social Psychology, 1987,53(3),pp500-510.

7. Hollenbeck, J. R., Williams, C. R., \& Klein, H. J. An empirical examination of the antecedents of commitment to difficult goals. Journal of Applied Psychology,1989,74(1)pp18-23.

8. Cialdini, R. B., \& Trost, M. R. (1998). Social influence:Social norms, conformity and compliance. In S. T. Fiske,D. T. Gilbert, \& G. Lindzey (Eds.), The handbook of social psychology (Vol. 2, 4th ed., pp. 151-192). Boston:

9. Muraven, M., Tice, D. M., \& Baumeister, R. F. (1998).Self-control as a limited resource: Regulatory depletion patterns. Journal of Personality and Social Psychology, 1998,74(3), pp774-778.

10. McGraw-Hill.Mc Cullough,J.1.,and Ostrom,T.M.Repetition of highly similar messages and attitude chang. Journal of Applied psychology,1974,59(3),pp395-397. 